\title{
IGF-1 Induces Growth, Survival and Morphological Change of Primary Hepatocytes on a Galactose-bared Polymer through both MAPK and $\beta$-catenin Pathways
}

\author{
Anup Kumer Kundu, Masato Nagaoka, Ezharul Hoque Chowdhury, Shinichi Hirose, \\ Tadashi Sasagawa, and Toshihiro Akaike* \\ Department of Biomolecular Engineering, Graduate School of Bioscience and Biotechnology, Tokyo Institute \\ of Technology, 4259 Nagatsuta, Midori-ku, Yokohama 226-8501, Japan
}

\begin{abstract}
PVLA poly-( $N$-p-vinylbenzyl- $O$ - $\beta$-D-galactopyranosyl-D-gluconamide) is a glycopolymer composed of hydrophilic carbohydrate side chain and hydrophobic styrene polymer. The hydrophilic carbohydrate residue of PVLA can be recognized as a ligand for hepatocytes asialoglycoprotein receptor (ASGP-R), which is abundant on the hepatocyte cell surface. Adhering to the PVLA coated dishes, hepatocytes try to form aggregates that have a long time survival and also cells in these aggregates exhibit better maintenance of specific hepatocyte functions. Stimulation of the cells with IGF-1 in this culture condition results in the formation of lower aggregates. In addition to the morphological influences of IGF-1 to these cells, we have also found that IGF-1 transmits growth stimulatory responses to hepatocytes on PVLA through both mitogen activated protein kinase (MAPK) pathway and $\beta$-catenin pathways. The phosphorylation of MAPK can take place within 5 min of stimulation with IGF-1 and within at least $10 \mathrm{ng} / \mathrm{ml}$ of IGF-1 concentration. Inhibition of MAPK activation by MEK-1 inhibitor PD98059 reduces IGF-1 induced MAPK phosphorylation, and also IGF-1 stimulated DNA synthesis. Similarly, the use of PI3-K inhibitor LY294002 also inhibits IGF-1 stimulated DNA synthesis. IGF-1 stimulation enhances the migration of $\beta$-catenin from the cytoskeleton and cell membrane to the cytoplasm which also is the reason behind formation of spheroids and lower aggregates. IGF-1 stimulation also shows increased translocalization of $\beta$ catenin to the nucleus that is essentially important to produce $\beta$-catenin responsive effects to the cells. These studies thus suggest that IGF-1 can stimulate the growth and survival of hepatocytes on PVLA through both MAPK and $\beta$-catenin signaling pathways, and that the activation of $\beta$-catenin signaling pathway produces the morphological changes of IGF-1 induced cells.
\end{abstract}

Key words: IGF-1/MAPK/proliferation/PVLA/ $\beta$-catenin

The extracellular matrix (ECM) is a biologically active tissue comprising glycoproteins and glycosaminoglycans, which forms a network through a number of specific interactions between different ECM components. The ECM serves a structural function but also affects cell adhesion,

\footnotetext{
*To whom correspondence should be addressed: Toshihiro Akaike, Professor, Department of Biomolecular Engineering, Graduate School of Bioscience and Biotechnology, Tokyo Institute of Technology, 4259 Nagatsuta, Midori-ku, Yokohama 226-8501, Japan.

Tel: +81-45-924-5790, Fax: +81-45-924-5815

E-mail: takaike@bio.titech.ac.jp

Abbreviations: IGF-1, insulin like growth factor-1, ASGP-R, asialoglycoprotein receptor, PVLA, poly- $N$ - $p$-vinylbenzyl- $O$ - $\beta$-D-galactopyranosylD-gluconamide, BrdU, 5-bromo-2-deoxyuridine, MAPK, mitogen-activated protein kinase, PI3-K, phosphotidylinositol 3-kinase, ECM, extracellular matrix.
}

differentiation, migration and proliferation (Hansen et al., 1994). Nowadays many researchers have paid attention to the interaction of cells with ECM molecules. Adhesion of cells on the ECM molecules results in the activation of intracellular pathways that permit cell cycle progression. For instance, hepatocyte proliferation is inhibited when these cells are plated on collagen gel, which promotes a differentiated phenotype of these cells (Hansen and Albrecht, 1999). Depending on the importance of cell-cell and cell-matrix interaction, many researchers have paid attention to the synthesis of artificial biocompatible materials for the culture of different cells which opens a new area of science known as tissue engineering. In this study, we have used PVLA for the culture of primary hepatocytes. PVLA (poly- $N$ - $p$-vinylbenzyl- $O$ - $\beta$-D-galactopyranosyl-D-glucona- 
mide) is a glycopolymer consisting of carbohydrate side chain with styrene polymers (Kobayashi et al., 1994). The interaction between hepatocytes and PVLA was carried out via asialoglycoprotein receptors (ASGP-R). Primary hepatocytes express high amounts of ASGP-R (Stockert, 1995). The ASGP-R is a transmembrane glycoprotein that recognizes galactose or $\mathrm{N}$-acetylgalactosamine residues of diasialylated glycoproteins and it can be endocytosed into hepatocytes. PVLA has galactose residues, which act as a ligand that can be recognized by ASGP-R on the hepatocyte cell surface. Due to the presence of the amphiphilic structural unit composed of hydrophilic carbohydrate and hydrophobic vinylbenzyl moiety, PVLA can be easily adsorbed at various densities on polystyrene dishes (Kobayashi et al., 1994). Due to its amphiphilic nature and sound interactions with the ASGP-R, PVLA was established as a good artificial matrix for hepatocytes.

On the other hand, IGF-1 was identified as a potent mitogen and growth stimulatory factor for several kinds of cells. The liver is the main source of circulating IGF-1 (Sjorgren et al., 1999). Recently, IGF-1 has gained attention for its multifunctional activities to different cell types (Taylor and Alexander, 1993). In addition to its well known biological and metabolic effects such as protein and glucose synthesis, proteoglycan synthesis, increased monocyte addition and cell migration, it has been shown to have distinct regulatory effects on cell growth through activation of its cognate IGF-1R (IGF-1 receptor). Though the downstream signaling pathway of IGF-1 has been examined in different cells mainly transformed and cancerous cells, no study has been performed in primary hepatocytes. Briefly, the binding of appropriate ligands with IGF-1R, a tetrameric glycoprotein composed of two $\alpha$ and two $\beta$ subunits, leads to autophosphorylation of some tyrosine residues on its $\beta$ subunits. This results in the recruitment and subsequent tyrosine phosphorylation of intracellular substrates including IRS-1, IRS-2, Shc and Grb2 (Werner and LeRoith, 1997). Subsequent to the initial events, two major intracellular signaling pathways, the mitogen-activated protein kinase (MAPK) and phosphotidylinositol 3-kinase (PI3-K) pathways are activated which have been shown to lead to diverse biological responses ranging from stimulating proliferation, differentiation, migration and inhibition of apoptosis in mammalian systems (Werner and LeRoith, 1997). In addition, activation of $\beta$-catenin is involved in the survival of cells. $\beta$-catenin was originally identified as a cytoplasmic protein that binds with the intracellular domain of E-cadherin linking it to the actin cytoskeleton via $\alpha$-catenin (Ben-ze'ev and Geiger, 1998). It interacts with a wide variety of protein partners, including the protein product of adenomatous polyposis coli (APC), glycogen synthase kinase-3 $\beta$ (GSK-3 $\beta$ ) and axin (Behrens et al., 1998). The interaction among them can be modulated by Wnt signaling which leads to the accumulation of hypophosphorylated $\beta$-catenin in the cytoplasm through inhibiting GSK-3 $\beta$. Once stabilized, $\beta$-catenin translocates to the nucleus where it associates with the transcription factors of the Lef/Tcf family to stimulate the expression of the Wnt-responsive genes (Cadigan and Nusse, 1997). The stimulatory effect of IGF-1 results in the activation and stabilization of $\beta$-catenin in the cytoplasm, which in turn exerts a growth stimulatory effect in some cell systems like colorectal cancer or melanoma cells (Playford et al., 2000; Desbois-Mouthon et al., 2001), but has not been examined in hepatocytes. In the present study, we have cultured hepatocytes on PVLA in presence of IGF-1 stimulation. Though some reports in our laboratory indicate the formation of spheroids or lower aggregates on PVLA in the presence of growth factors, we have shown more precisely that the activation of $\beta$-catenin signaling pathway is mainly involved in this morphological transition of hepatocytes by IGF-1. Moreover this study not only focuses IGF-1 induced morphological transition of hepatocytes on PVLA, but also reveals the downstream signaling pathways of this growth factor IGF-1, in these cells.

\section{Materials and Methods}

\section{Materials}

IGF-1 was obtained from Sigma (St. Louis, MO). Antibody to $\beta$ catenin and Erk-2 were obtained from BD Transduction Laboratories (Lexington, KY). Antibody to p44/42-MAPK (monoclonal antibody) was purchased from Cell Signaling Technology, Inc. (Beverly, MA). Horseradish peroxidase conjugated secondary antimouse antibody was purchased from Jackson ImmunoResearch Laboratories, Inc. (Baltimore, PA). MEK-1 inhibitor PD98059 and PI3-K inhibitor LY294002 were purchased form Cell Signaling Technology, Inc. (Beverly, MA). Precision Plus Protein Standards and Prestained SDS-PAGE Standards (low range) were obtained from Bio-Rad Laboratories, Inc. (Hercules, CA). Fetal bovine serum and antibiotics were purchased from Sigma. All cell culture reagents were obtained from Iwaki, Japan.

\section{Isolation of primary hepatocytes}

Primary hepatocytes were isolated from male ICR (5-8 weeks) mouse purchased from Sankyo Lab Service Co., Inc. (Tokyo, Japan). Animal care was carried out by the standard protocol of animal use and care. Hepatocytes were isolated using the modified in situ collagenase perfusion methods described previously (Morita et al., 1994). Cells were removed by Percoll (Pharmacia, NJ) with density gradient centrifugation and viable hepatocytes were suspended in serum free William's E (WE) medium (Life Technologies) containing antibiotics $(50 \mu \mathrm{g} / \mathrm{ml}$ penicillin, $50 \mu \mathrm{g} /$ $\mathrm{ml}$ streptomycin, and $100 \mu \mathrm{g} / \mathrm{ml}$ neomycin). These cells were then plated at a density of $2.5 \times 10^{4}$ cells $/ \mathrm{cm}^{2}$ on PVLA $(50 \mu \mathrm{g} / \mathrm{ml})$ coated culture dishes in serum free WE medium and incubated in humidified $5 \% \mathrm{CO}_{2}$ chamber at $37^{\circ} \mathrm{C}$ for $4 \mathrm{~h}$, the medium was changed once and preserved in that condition. Before plating, cells were judged to be greater than $90 \%$ viable. 


\section{Preparation of PVLA coated dish}

Synthesis of PVLA was carried out as described (Kobayashi et al., 1992). For the preparation of PVLA coated dish, aqueous solutions of PVLA at the indicated final concentrations were prepared and sonicated for $10 \mathrm{~min}$ before use. The plates were incubated with aqueous PVLA solution overnight. Then after washing with water twice, the plates were blocked with $0.5 \%$ BSA-PBS for $2 \mathrm{~h}$. Finally the plates were washed and dried for $1 \mathrm{~h}$ before being used for cell culture.

\section{Analysis of DNA synthesis}

The DNA synthesis of hepatocytes was measured by the modified 5-bromo-2-deoxy-uridine (BrdU) uptake method described previously (Muir et al., 1990). Briefly, hepatocytes were cultured at $2.5 \times 10^{4}$ cells $/ \mathrm{cm}^{2}$ on PVLA coated 96-well non-tissue culture dish for $24 \mathrm{~h}$ in WE medium without FBS. Cells were pretreated either with DMSO or with PD98059 and LY294002 at the concentrations indicated for $2 \mathrm{~h}$, followed by treatment with IGF-1 for 2 days. Then cells were incubated with BrdU, and DNA synthesis was measured in terms of the incorporation of BrdU into the DNA using the cell proliferation ELISA system version 2 (Amersham Pharmacia Biotech.), BrdU Labeling and Detection kit (Roche Diagnostics Co., Mannheim, Germany) following the manufacturer's instructions.

\section{Western blot detection of MAPK and p-MAPK}

The cells were lysed with Nonidet p-40 lysis buffer containing 1\% Nonidet P-40, $150 \mathrm{mM} \mathrm{NaCl}, 50 \mathrm{mM}$ Tris $\mathrm{pH} 8.0$ including $1 \mu \mathrm{g} /$ $\mathrm{ml}$ aprotonin, $1 \mu \mathrm{g} / \mathrm{ml}$ leupeptin, $10 \mu \mathrm{g} / \mathrm{ml}$ phenylmethylsulfonyl fluoride (PMSF) plus $10 \mu \mathrm{M}$ sodium orthovandate. Lysates were clarified by centrifugation at $15,000 \mathrm{rpm}$ for $30 \mathrm{~min}$ at $4^{\circ} \mathrm{C}$ and the supernatant containing different protein molecules was separated from the insoluble pellets. The protein amount of the lysate was determined using DC protein assay kit (Bio-rad, CA). In case of Western blot detection of phospho-MAPK, equal amounts of proteins were separated by $12 \%$ SDS-PAGE in reducing condition. After separation of the proteins, they were transferred to nitrocellulose filter paper and $80 \mathrm{~mA}$ current supply was applied for $90 \mathrm{~min}$ to complete transfer of the proteins. The nitrocellulose filter papers containing the protein molecules were washed twice with PBS(-) containing $0.1 \%$ Tween 20 and then blocked overnight with PBS-T containing $3 \%$ bovine serum albumin (BSA). The membranes were incubated with an anti-p-MAPK antibody which can recognize the phosphorylated form of both Erk-1 and Erk-2 for $2 \mathrm{~h}$ in room temperature. Blots were then washed for three times with sufficient amount of PBS-T and again incubated with horseradish peroxidase conjugated secondary antibody for 1$2 \mathrm{~h}$. After the incubation period, the membranes were washed again with PBS-T three to four times to completely remove unspecific interactions. Enhanced chemiluminescence system (Amersham Pharmacia Biotech) was used for visualization. After the detection of p-MAPK, the membranes were probed again for the detection of MAPK. For that reason the membranes were immersed in stripping buffer containing $100 \mathrm{mM}$ 2-mercaptoethanol, 2\% sodium dodecyl sulphate (SDS), $62.5 \mathrm{mM}$ Tris- $\mathrm{HCl}$ $\mathrm{pH} 6.7$ for $30 \mathrm{~min}$ at $50^{\circ} \mathrm{C}$ with occasional agitation. The membranes were then washed twice with $75 \mathrm{ml}$ washing buffer for 10 min in every time. The membranes were blocked again in blocking buffer. The detection of MAPK by using an anti-Erk-2 antibody was carried out in a similar way described earlier.

\section{Cell fractionation experiments}

Hepatocytes were cultured on PVLA $(50 \mu \mathrm{g} / \mathrm{ml})$, serum starved for $12 \mathrm{~h}$, and stimulated with or without IGF-1 $(50 \mathrm{ng} / \mathrm{ml})$ for the indicated time period. The cells were lysed with digitonin lysis buffer (1\% digitonin, $150 \mathrm{mM} \mathrm{NaCl}, 50 \mathrm{mM}$ Tris-HCL, pH 7.5, $10 \mathrm{mM}$ $\mathrm{MgCl}_{2}$ and $10 \mu \mathrm{g} / \mathrm{ml}$ PMSF, $1 \mu \mathrm{g} / \mathrm{ml}$ leupeptin and $1 \mu \mathrm{g} / \mathrm{ml}$ aprotonin) and the lysate were centrifuged at $15000 \mathrm{rpm}$ for $10 \mathrm{~min}$. The supernatant containing soluble portion was saved. The pellets representing insoluble fraction were lysed in RIPA buffer (150 $\mathrm{mM} \mathrm{NaCl}, 0.5 \%$ sodium deoxycholate, $0.1 \%$ SDS, $50 \mathrm{mM}$ Tris, $\mathrm{pH} 7.5,1 \%$ Nonidet P-40) and supernatants were collected. Equal amount of proteins were separated on 7.5\% SDS-PAGE gels under reducing condition and transferred to nitrocellulose filter. The membranes were washed twice with PBS containing $0.1 \%$ Tween 20 and blocked overnight with PBS-T containing 5\% BSA. The membranes were then analyzed with antibody to $\beta$-catenin.

\section{Immunofluorescence light microscopy}

Hepatocytes were plated onto Lab-tek Chamber Slides and incubated at $37^{\circ} \mathrm{C}$ overnight. To examine the localization of activated $\beta$-catenin, cells were serum starved for $20 \mathrm{~h}$ and then stimulated with or without $50 \mathrm{ng} / \mathrm{ml} \mathrm{IGF-1} \mathrm{for} \mathrm{the} \mathrm{indicated} \mathrm{time} \mathrm{period.} \mathrm{The}$ slides were washed twice with PBS(-), and cells were fixed with $4 \%$ formaldehyde for $10 \mathrm{~min}$ and permeabilized with $0.2 \%$ Triton $\mathrm{X}-100$ in PBS for $2 \mathrm{~min}$. Then $\beta$-catenin was visualized by incubating cells with an anti- $\beta$-catenin antibody followed by Alexa Fluor 488-conjugated secondary antibody. The nucleus was stained with propidium iodide (PI).

\section{Results}

The morphology of hepatocytes on PVLA coated dishes in presence or absence of IGF-1 stimulation is described in Fig. 1. To differentiate the morphological changes, it was compared with that on type 1 collagen-coated dishes. On collagen-coated matrix, hepatocytes showed spreading that gradually increased with the increase of incubation period. IGF-1 stimulation did not make any substantial change in the morphology of hepatocytes on collagen dishes. A different type of cell morphology could be found on PVLAcoated culture dishes. When hepatocytes were cultured on $50 \mu \mathrm{g} / \mathrm{ml}$ PVLA-coated dishes for $24 \mathrm{~h}$, cells tried to spread but this spreading phenomenon was lower than that on collagen dishes. At the same time when the cells on PVLA dishes were stimulated with IGF-1 for $24 \mathrm{~h}$, a major portion of cells became rounded and formed spheroids. This mor- 

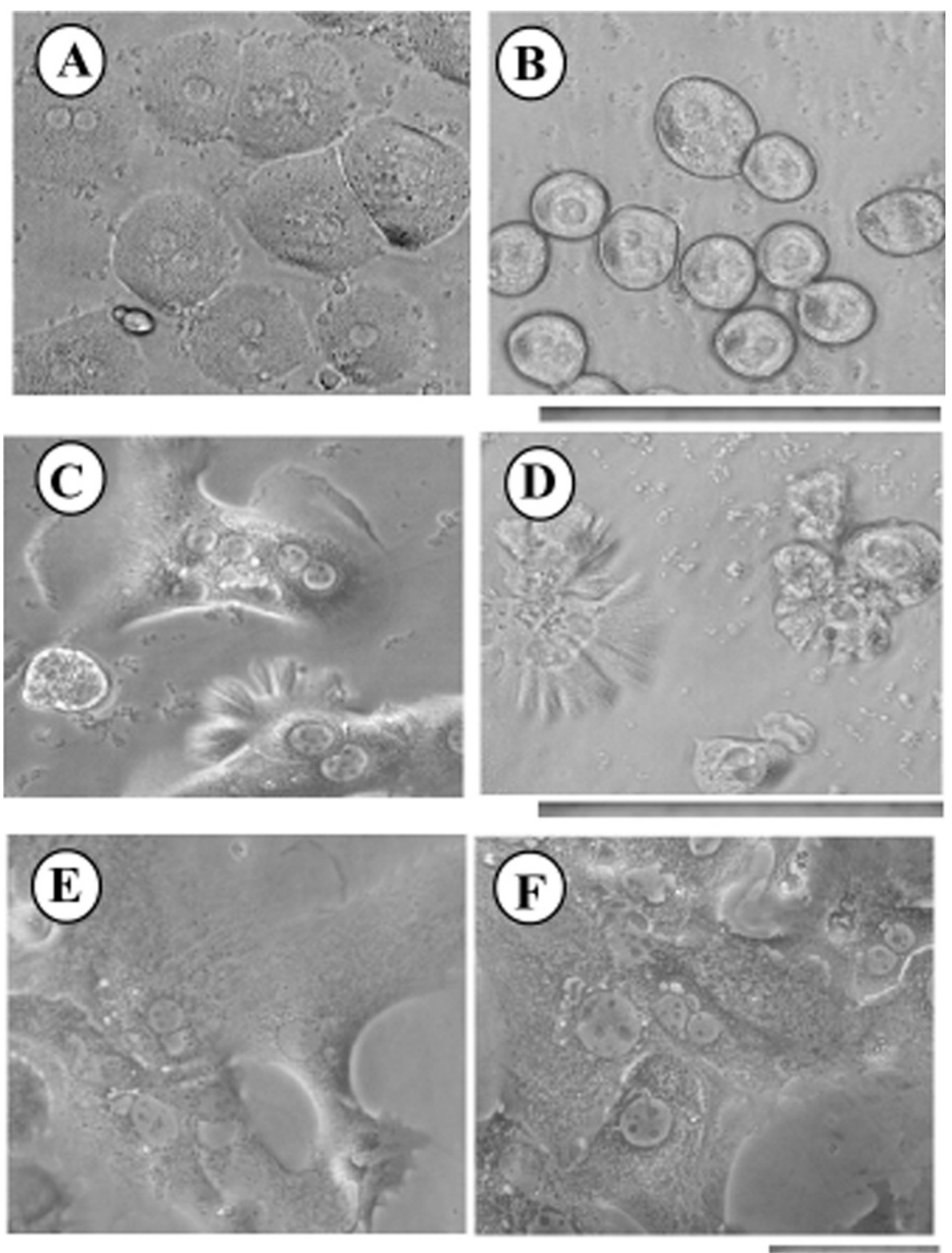

Fig. 1. Comparison of the effect of IGF-1 stimulation on the morphology of primary hepatocytes on PVLA and collagen. Cells were cultured on $50 \mu \mathrm{g} / \mathrm{ml}$ PVLA (B, C, D) and $0.01 \%$ type 1 collagen (A, E, F) in WE medium without FBS. Fig (A and B) represents cells cultured for $4 \mathrm{~h}$ in absence of growth factors and Fig. (C, D, E, and F) represents cells cultured for $24 \mathrm{~h}$ in which the cells were stimulated with $50 \mathrm{ng} / \mathrm{ml} \mathrm{IGF-1} \mathrm{(D} \mathrm{and} \mathrm{F)} \mathrm{and} \mathrm{the} \mathrm{other} \mathrm{two} \mathrm{(C} \mathrm{and}$ E) remained unstimulated. Morphological changes were observed by phase contrast microscope. Scale bar represents $50 \mu \mathrm{m}$.

phological transition of hepatocytes on PVLA-coated dishes in presence of IGF-1 stimulation initiated us to examine the downstream signaling effects of IGF-1 in these cells.

At an initial stage, in order to define the signaling pathways that mediate the effects of IGF-1 on different systems, the ability of IGF-1 to activate different signaling pathways in hepatocytes was examined. Initial studies examined the effect of IGF-1 in the activation of MAPK pathway. To determine whether MAPK is activated in primary hepatocytes by IGF-1, serum starved cells were treated for varying periods with $50 \mathrm{ng} / \mathrm{ml}$ IGF-1, and then Western blot analysis was performed using phospho-specific and control antibodies to MAPK. As shown in Fig. 2A, the IGF-1 induced MAPK phosphorylation was observed within 5 min of stimulation and the maximum activity of this protein was found within 10 min of the exposure to IGF-1. Similarly, a dose dependent activation of MAPK by IGF-1 was observed in these cells (Fig. 2B). While treated for 10 min with IGF-1, phosphorylation of MAPK was shown to start within at least $10 \mathrm{ng} / \mathrm{ml}$ concentration of IGF-1 and the phosphoryla- 
A.

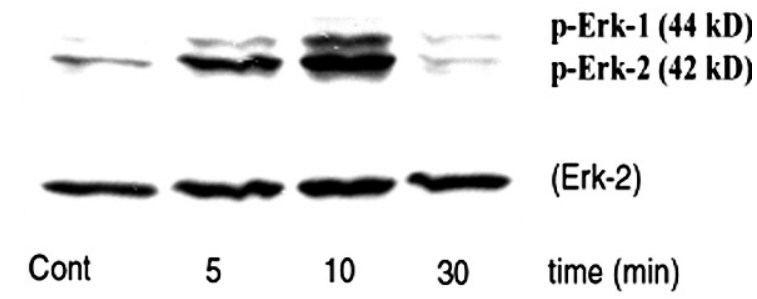

B.

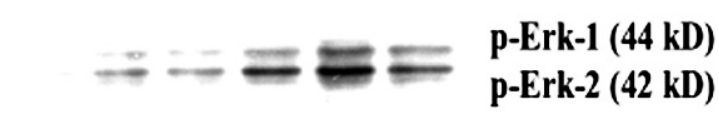

Erk-2

\section{$\begin{array}{lllllll}0 & 10 & 20 & 50 & 100 & 200 & \text { IGF-1(ng/ml) }\end{array}$}

Fig. 2. A. IGF-1 stimulation leads to rapid and transient activation of MAPK. Mouse primary hepatocytes cultured on PVLA $(50 \mu \mathrm{g} / \mathrm{ml})$, were serum starved for $24 \mathrm{~h}$ and then stimulated with or without IGF-1 (50 ng/ $\mathrm{ml}$ ) for various period of time. Lysates were subjected to Western blotting with an anti-phospho-MAPK antibody. Later the membrane was stripped out and reblotted with an anti-Erk-2 antibody. The experiment was performed three times using different cell lysate. B. Dose dependent effect of IGF-1 on MAPK phosphorylation. Serum starved cells were stimulated with IGF-1 at different concentrations for $10 \mathrm{~min}$. Equal amounts of proteins were separated by $12 \%$ SDS-PAGE and transferred to nitrocellulose filter paper. The phosphorylated level of MAPK was determined by using an anti-phospho-MAPK antibody. The membrane was then stripped out and blotted again with an anti-Erk-2 antibody.

tion was increased with the increasing concentration of IGF-1. Thus it was found that the effect of IGF-1 on MAPK activation was rapid and transient. To determine whether IGF-1 can stimulate MAPK phosphorylation in a MEKdependent manner, the effect of PD98059, a potent and selective inhibitor of MEK-1 (Alessi et al., 1995), on IGF-1 induced MAPK phosphorylation was examined. The phosphorylation of MAPK was inhibited by $50 \mu \mathrm{M}$ PD98059 with or without IGF-1 (Fig. 3). Then in respect to the activation of MAPK pathway by IGF-1, we tried to determine whether this activation was also involved in the mitogenic activity of IGF-1 to these cells. Cells were pretreated with this specific inhibitor of MAPK PD98059, for $2 \mathrm{~h}$ and then stimulated with IGF-1 for another 2 days. As shown in Fig. 4, the DNA synthesis activity of IGF-1 was found to be reduced by this inhibitor. We have also found that PD98059 inhibited IGF-1 induced DNA synthesis in a dose dependent manner (data not shown). In addition to the MAPK pathway, the PI3-K pathway has been shown to mediate the mitogenic and differentiating effect of IGF-1 in different systems. We therefore studied the effect of PI3-K inhibition

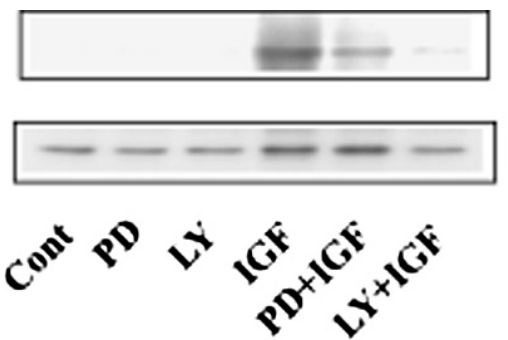

p-Erk-1/Erk-2

Erk-2

Fig. 3. Effect of PD98059 and LY294002 on IGF-1 induced MAPK activation. Mouse primary hepatocytes were cultured on PVLA, serum starved for less than $24 \mathrm{~h}$ and then treated with or without PD98059 $(50 \mu \mathrm{M})$ or LY294002 $(50 \mu \mathrm{M})$ for $2 \mathrm{~h}$ followed by stimulation with or without IGF-1 $(50 \mathrm{ng} / \mathrm{ml})$ for $10 \mathrm{~min}$. Phospho-MAPK level was detected by Western blot analysis as described in Materials and Methods. After detection of phospho-MAPK, the blot was reprobed with an antibody directed against Erk-2.

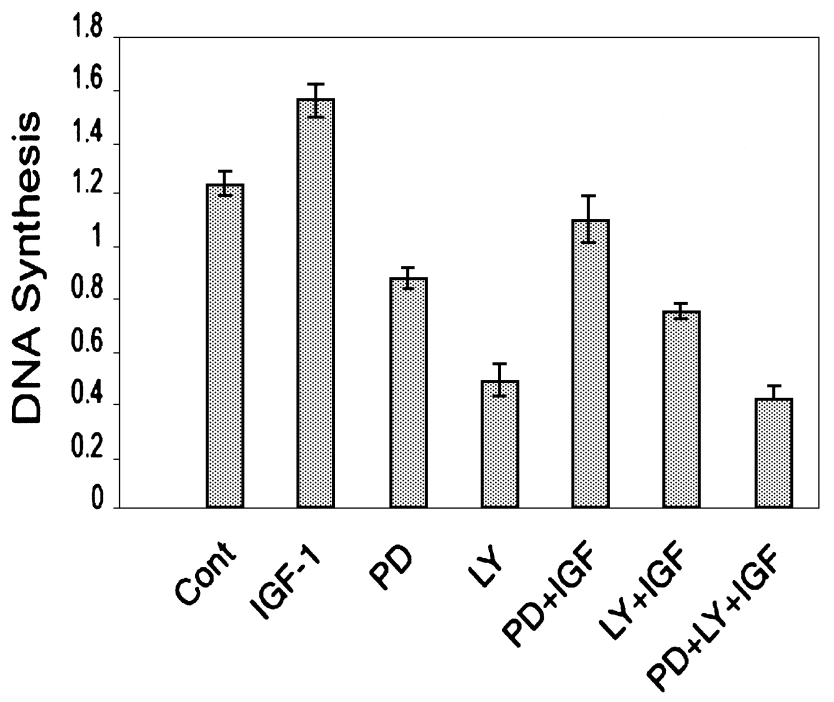

Fig. 4. Effect of MEK-1 inhibitor PD98059 and PI3-K inhibitor LY294002 on IGF-1 induced DNA synthesis of mouse primary hepatocytes cultured on PVLA. After $24 \mathrm{~h}$ serum starvation, hepatocytes were pretreated with or without $50 \mu \mathrm{M}$ PD98059 and $50 \mu \mathrm{M}$ LY294002 for $2 \mathrm{~h}$, followed by stimulation with DMSO (control) or IGF-1 $(50 \mathrm{ng} / \mathrm{ml})$ for 2 days. The rate of DNA synthesis was carried out by BrdU proliferation test described in Materials and Methods. The mean value \pm SD of triplicate cultures is shown.

in our system (Fig. 4). Pretreatment of cells with specific PI3-K inhibitor LY294002, for $2 \mathrm{~h}$ also reduced IGF-1 stimulated BrdU incorporation into the DNA of these cells. All of these results indicated that the activation of both MAPK and PI3-K pathways are required for the mitogenic action of IGF-1 in these cells.

We next investigated the effect of IGF-1 stimulation on the translocalization and stabilization of $\beta$-catenin in mouse primary hepatocytes via cell fractionation experiments (Playford et al., 2000). After 10- and 30-min IGF-1 stimulation of the $12 \mathrm{~h}$ serum starved cells, cell suspensions were lysed by digitonin lysis buffer. The solubilized portion of 


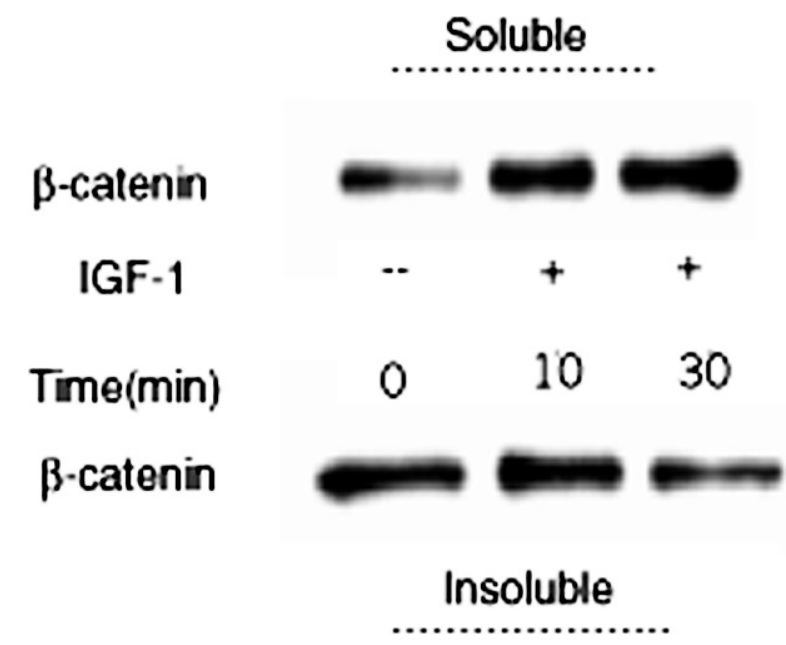

Fig. 5. Effect of IGF-1 on the localization of $\beta$-catenin between cytoplasmic and cell cytoskeleton components in mouse primary hepatocytes cultured on PVLA. Hepatocytes were serum starved for $12 \mathrm{~h}$ and then stimulated with or without IGF-1 $(50 \mathrm{ng} / \mathrm{ml})$ for $10 \mathrm{~min}$ and $30 \mathrm{~min}$. Cell suspension was fractionated into digitonin (soluble fraction) and Ripa (insoluble fraction) fractions. Equal amounts of protein in each fraction were separated by $7.5 \%$ SDS-PAGE and the relative level of $\beta$-catenin in different fractions was determined by Western blot analysis using an anti- $\beta$-catenin antibody. The experiment was performed three times using different cell lysate.

the cell lysate, which contains cytoplasmic and nuclear proteins, was then separated from the pellet, and the pellet, which contains mainly cytoskeleton and cell membrane proteins, was again lysed by RIPA lysis buffer. Immunoblot analysis of $\beta$-catenin showed that after $30 \mathrm{~min}$ stimulation with IGF-1, the level of $\beta$-catenin was increased in the soluble fraction whereas it was decreased in the insoluble fraction (Fig. 5). Consistent with this finding, immunofluorescence staining of hepatocytes for $\beta$-catenin without any IGF-1 stimulation showed no $\beta$-catenin level in the nucleus but when the cells were stimulated with IGF-I for $30 \mathrm{~min}$, there was a drastic change in the localization of this protein. Most of the free proteins were found to be translocated to the nucleus (Fig. 6). These results suggested that IGF-1 might contribute to the survival of primary hepatocytes by stabilizing $\beta$-catenin in the cytoplasm and then translocating it to the nucleus.

\section{Discussion}

Extracellular matrix (ECM) plays a pivotal role in cell functions in tissue, as well as in the structural components that link cell to cell. Cell adhesion to ECM is essential for tissue development, differentiation, growth and tumor formation in animal tissue (Kubota et al., 1992). The differences in the interaction of cells with ECM molecules have also drawn the attention of many researchers. In addition to the use of the natural ECM, interest also is gradually increasing as to use of synthetic matrix for the culture of cells. Carbohydrate based synthetic matrix has been found to be an important tool in tissue engineering and in vitro usages. The most extensively studied example is the use of monosaccharide binding to ASGP-R on hepatocytes (Geffen and Spiess, 1992). Although the ASGP-R does not normally function as an adhesion receptor, carbohydrate containing polymers have been used to induce the selective adhesion to primary hepatocytes (Kobayashi et al., 1992). Depending on this principle, Kobayashi et al. have synthesized a lactose-bearing glycopolymer PVLA which acts as an artificial cell adhesion matrix for hepatocytes where the interaction between hepatocytes and PVLA was carried out via ASGPR. The hydrophilic carbohydrate side chain and hydrophobic vinylbenzyl moiety of PVLA make it more susceptible to be adsorbed at various densities on polystyrene dishes (Kobayashi et al., 1992; Kobayashi et al., 1994). Previous reports in our laboratory have also indicated that the specific functions as well as attachment of hepatocytes on PVLA coated dishes were successfully maintained (Watanabe et al., 2000; Kobayashi et al., 1992). Hepatocytes on PVLA coated dishes in presence of growth factors show distinct morphology. But no study has disclosed the reasons behind these morphological changes of hepatocytes on PVLA. Moreover the internal signaling of growth factors in hepatocytes in this culture condition has yet to be revealed. In the current study, we sought to disclose the internal factors regarding morphological transitions and also downstream signaling of IGF-1. In Fig. 1, we examined the morphological changes of primary hepatocytes cultured on PVLA and compared then with that on collagen coated dishes. We found that a different type of cell morphology exists on PVLA-coated culture dishes, and that even the morphology of the cells is dependent on the concentration of PVLA used for cell culture (data not shown). The stimulatory effects of IGF-1 to hepatocytes on $50 \mu \mathrm{g} / \mathrm{ml} \mathrm{PVLA}$ prevents them from being elongated and helps them to form spheroids which is the functional state of hepatocytes on PVLA coated dishes. On the other hand after $4 \mathrm{~h}$ of the adhesion period, in the presence of IGF-1 stimulation, hepatocytes on PVLA of low-density coated (i.e. $0.5 \mu \mathrm{g} / \mathrm{ml}$ of PVLA or less than that amount) dishes were more spreading than on high-density coated dishes $(\geq 100 \mu \mathrm{g} / \mathrm{ml})$ and after $24 \mathrm{~h}$ of adhesion period, they formed lamellipodium and philopodium extensions on low density coated dishes whereas they had lower aggregation and formed spheroids on high density coated dishes. IGF-1 stimulation thus made a visible difference in the morphology of hepatocytes on PVLA coated dishes, which also led us to investigate the internal signaling cascade of IGF-1 in these cells.

In this study, we have used IGF-1 as a potent mitogen and growth stimulatory factor. The multifunctional activities of IGF-1 to different cell types are performed through the activation of IGF-1R. Acting either alone or in concert with other growth factors, IGF-1 can induce proliferation and 


\section{Control no stimulation}
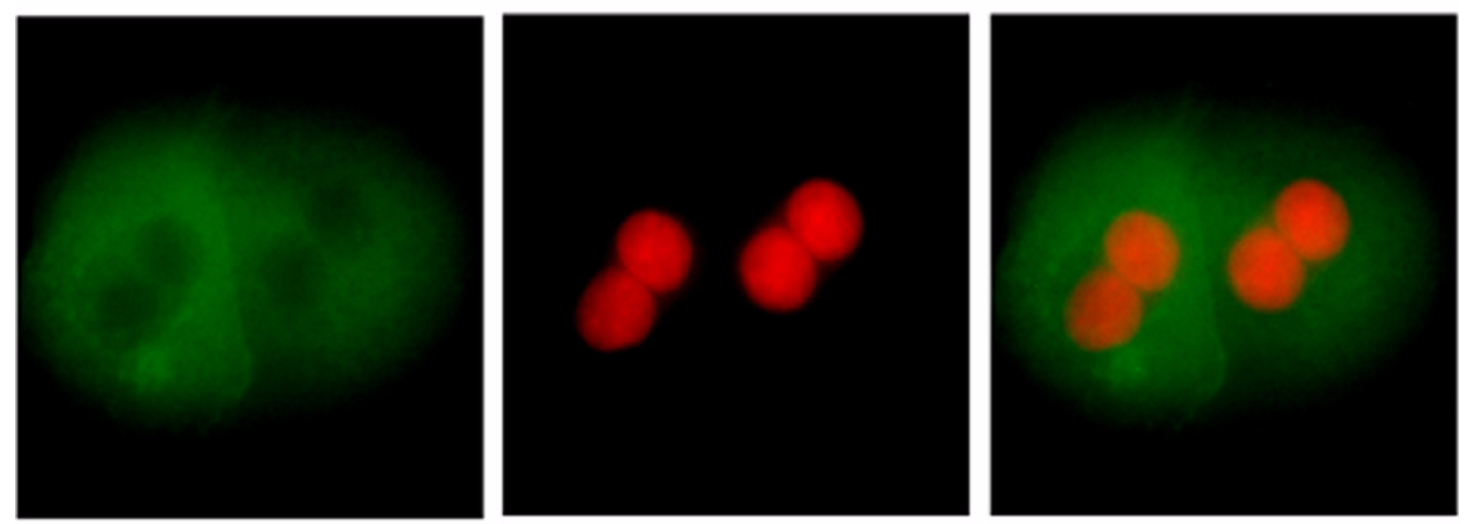

\section{0 min stimulation with IGF-1}

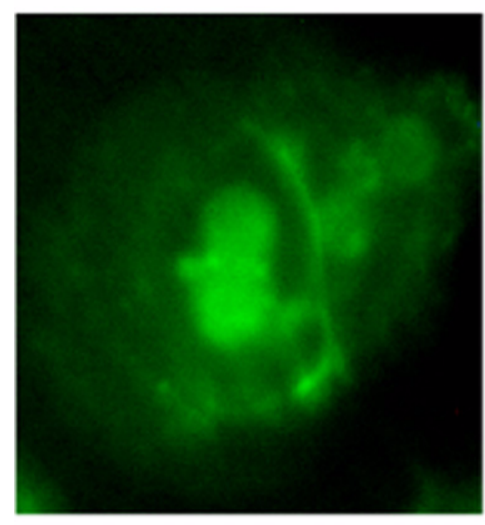

$\beta$-catenin

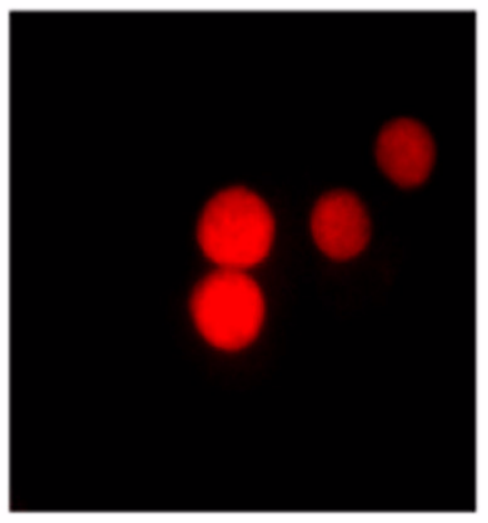

Nucleus

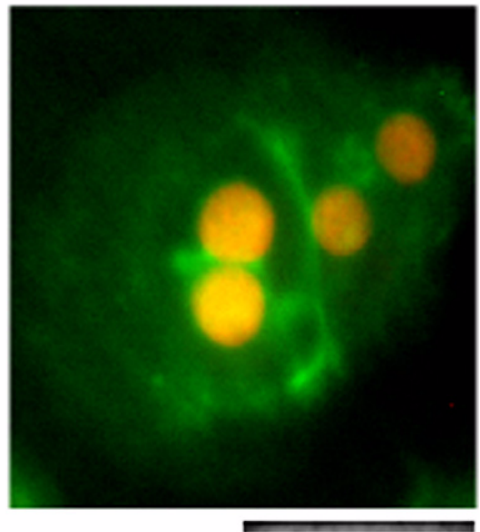

Merged

Fig. 6. Effect of IGF-1 stimulation on the translocalization of $\beta$-catenin in mouse primary hepatocytes. Hepatocytes, cultured on PVLA, were serum starved for $20 \mathrm{~h}$ and then stimulated with vehicle control or $50 \mathrm{ng} / \mathrm{ml} \mathrm{IGF}-1$ for $30 \mathrm{~min}$ at $37^{\circ} \mathrm{C}$. Cells were fixed by formaldehyde and then incubated with an anti- $\beta$-catenin antibody which was visualized with Alexa Fluor 488 conjugated secondary antibody. Nucleus was stained with PI. Scale bar represents $50 \mu \mathrm{m}$.

growth of many mammalian cells, including adipocytes, epithelial cells, fibroblasts and muscle cells (Desbois-Mouthon et al., 2001; Kamai et al., 1996; Poizios et al., 2001; Kuemmerle and Bushman, 1998). IGF-1 signaling protects myoblast and PC-12 cells from apoptosis (Napier et al., 1999). By considering these multifunctional properties of IGF-1, we have tried to determine the effect of IGF-1 on primary hepatocytes. In mammals, two types of IGF-R, type I and type II have been characterized in addition to the insulin receptor. The biological actions of IGFs are thought to be mediated through interaction with IGF-1R. Previous studies have indicated the presence of IGF-1R on the hepatocyte cell surface (Soni et al., 2000; Froesch et al., 1985; Caro et al., 1988). But the IGF-1 signal transduction pathways in primary hepatocytes have not been well studied. Studies using mammalian model systems (mostly tumor and transformed cell line) indicate that one of the earliest steps in signal transduction by the IGF-1R is the phosphorylation of adaptor/docking proteins such as IRS-1, IRS-2, Shc, Grb2 and Grb10 (Werner and LeRoith, 1997). These molecules then interact with downstream signal molecules, resulting in the activation of MAPK and PI3-K signaling pathways. In this study we have found that IGF-1 can cause a rapid and transient activation of MAPK in primary hepatocytes. The activation of this protein is time and concentration dependent. The protein can be phosphorylated within $5 \mathrm{~min}$ of IGF1 stimulation and within at least $10 \mathrm{ng} / \mathrm{ml}$ concentration. But we have found the maximum intensity of phosphorylation of MAPK after 10 min of stimulation with IGF-1. Similarly, IGF-1 at the concentration of $50-100 \mathrm{ng} / \mathrm{ml}$ can pro- 
duce maximum activation of this protein (Fig. 2B). In another experiment it was found that the activation of MAPK by IGF-1 was inhibited by PD98059, a specific inhibitor of MEK-1 (Fig. 3). Then we checked PD98059's dose dependent inhibition of IGF-1 induced DNA synthesis activity and found that IGF-1 stimulated DNA synthesis activity of these cells are maximally inhibited by $50 \mu \mathrm{M}$ of PD98059. Selective inhibition of MAPK activation by PD98059 is also correlated with the decreased IGF-1 induced DNA synthesis activity of these cells by this inhibitor. These results thus suggest that MAPK activation is critical for IGF-1 induced cell growth and proliferation of these cells. In addition to MAPK pathway, we also checked the contributory role of PI3-K pathway in IGF-1 induced DNA synthesis activity. We have found that $\mathrm{BrdU}$ incorporation into the growing DNA of IGF-1 stimulated cells was reduced when the cells were pretreated with the specific PI3-K inhibitor LY294002, and also that LY294002 inhibited IGF-1 stimulated DNA synthesis activity in a dose dependent manner. The results indicate that in addition to MAPK pathway, the PI3-K pathway is also involved in IGF-1 action on these cells.

Cell survival by IGF-1 is mainly mediated through the activation of the PI3-K pathway and/or in combination with the activation of MAPK pathway. Activation of PI3-K pathway also results in the inhibition of GSK-3 $\beta$ and stabilization of $\beta$-catenin. Earlier studies have indicated that signaling from growth factors (e.g. insulin) to GSK-3 $\beta$ is sensitive to wortmannin, a potent inhibitor of Akt activation (Cross, 1995). Like Wnt signaling, the signal from insulin leads to the accumulation of $\beta$-catenin via inhibition of GSK-3 $\beta$, whereas other reports indicate that growth factors like hepatocyte growth factor and intestinal trefoil factor increase the level of free cytoplasmic level of $\beta$-catenin caused by tyrosine phosphorylation (Hiscow and Jiang, 1997). But since no study has described the stimulatory effect of IGF- 1 on the $\beta$-catenin signaling pathways in hepatocytes, we next investigated the effect of IGF-I stimulation on the translocalization and stabilization of $\beta$-catenin in primary hepatocytes. In cell fractionation experiment shown in Fig. 5, we have found that after $30 \mathrm{~min}$ stimulation with IGF-1, the level of $\beta$-catenin increased in the soluble fraction whereas it decreased in the insoluble fraction. This result suggests that due to the stimulation of hepatocytes with IGF-1, many of the $\beta$-catenin protein molecules migrated from the cytoskeleton and cell membrane to the cell cytoplasm, and thus increased the cytoplasmic level of $\beta$-catenin. This $\beta$-catenin translocalization from membrane and cytoskeleton to the cytoplasm is likely to be involved in IGF-1 induced morphological transition of hepatocytes on PVLA. It is already known that the intracellular portion of cadherins associates with $\beta$-catenin, which then forms links with the actin cytoskeleton inside the cell, thus increasing adhesion (Wijnhoven et al., 2000). But due to the migration of $\beta$-catenin from cell membrane and cell cytoskeleton, catenins are dissociated from cadherins and thereby decrease adhesion and change cell morphology (Beavon, 2000; Conacci-Sorrell et al., 2002). From the results of the present experiment, it is clear that due to the stimulation of hepatocytes with IGF-1, many of the $\beta$-catenin molecules migrate from cell membrane and cytoskeleton to the cytoplasm and thereby destabilize the cadherin-catenin interactions which ultimately decrease cell-cell interactions. For that reason, we have found that due to IGF-1 stimulation, hepatocytes had lower aggregates and formed spheroids. Moreover, the elongated cellular morphology causes suppression of growth and a decrease in the density of cell cultures (Benvenuto et al., 2000; Li et al., 2003). We have found the formation of spheroids and fewer aggregates instead of formation of elongated cellular morphology of hepatocytes during stimulation period. This morphological transition also suggests the high growth rate of hepatocytes on PVLA. Following the examination of $\beta$-catenin translocalization between cell membrane and cell cytoskeleton to cell cytoplasm, we carried out immunofluorescence staining of $\beta$-catenin in hepatocytes with or without IGF-1 stimulation (Fig. 6). Immunofluorescence staining also revealed the effect of IGF-1 stimulation on the drastic changes of $\beta$-catenin localization between different cell compartments. Similar to Wnt signaling, where $\beta$-catenin translocating to the nucleus interact with Lef/Tcf transcription factors to increase the expression of $\beta$-catenin responsive genes, IGFI also increased the translocalization of $\beta$-catenin in the nucleus resulting in the downstream effects of this protein. All of the results clearly indicate that the stimulation of hepatocytes with IGF-1 on PVLA coated culture dishes decreased $\beta$-catenin levels from cell membrane which causes destabilization of cadherin-catenin interactions. Due to the destabilization of cadherin-catenin interactions, cells formed spheroids and became less aggregate. Moreover, increased $\beta$-catenin in the cytoplasm finally translocated to the nucleus where it activated $\beta$-catenin responsive genes and possibly contributed to the survival and growth of these cells. All these studies taken together produce a clear picture of the downstream effect of IGF-1 on primary hepatocytes cultured on PVLA. Although PVLA is shown to be a good substrate for culturing primary hepatocytes and IGF-1 treatment leads to increase cell survival and growth, the interplay between these two factors should be clarified further.

Acknowledgments. We wish to thank Dr. I. Harada, Dr. S.H. Kim and Dr. K. Megumi of Tokyo Institute of Technology for their helpful suggestions. This work was supported in part by Grants-in-Aid for Scientific Research from the Ministry of Education, Science, Sports and Culture of Japan.

\section{References}

Alessi, D.R., Cuenda, A., Cohen, P., Dudley, D.T., and Saltiel, A.R. 1995. PD98059 is a specific inhibitor of the mitogen-activated protein kinase kinase in vitro and in vivo. J. Biol. Chem., 270: 27489-27494. 
Beavon, I.R. 2000. The E-cadherin-catenin complex in tumor metastasis: structure, function and regulation. Eur. J. Cancer, 36: 1607-1620.

Behrens, J., Jerchow, B.A., Wurtele, M., Grimm, J., Asbrand, C., Wirth, R., Kuhl, M., Wedlich, D., and Birchmeier, W. 1998. Functional interaction of an axin homolog, conductin, with beta-catenin, APC, and GSK3 beta. Science, 280: 596-599.

Benvenuto, G., Li, S., Brown, S.J., et al. 2000. The tuberous sclerosis-1 (TSC1) gene product hamartin suppresses cell growth and augments the expression of the TSC 2 product tuberin by inhibiting its ubiquitination. Oncogene, 19: 6306-6316.

Ben-ze'ev, A. and Geiger, B. 1998. Differential molecular interactions of $\beta$-catenin and plakoglobin in adhesion, signaling and cancer. Curr. Opin. Cell Biol., 10: 629-639.

Cadigan, K.M. and Nusse, R. 1997. Wnt signaling: a common theme in animal development. Genes Dev., 11: 3286-3305.

Caro, F., Poulos, J., Ittoop, O., Pories, W.J., Flickinger, E.G., and Sinha, M.K. 1988. Insulin like growth factor-1 binding in hepatocytes from human liver, human hepatoma, and normal, regenerating, and fetal rat liver. J. Clin. Invest., 81: 976-981.

Conacci-Sorrell, M., Zhurinsky, J., and Ben-ze'ev, A. 2002. The cadherincatenin adhesion system in signaling cancer. J. Clin. Invest., 109: 987991.

Cross, D.A., Alessi, D.R., Cohel, P., Anduelkovich, M., and Hemmings, B.A. 1995. Inhibition of glycogen synthase kinase-3 $\beta$ by insulin mediated by protein kinase B. Nature, 378: 785-789.

Desbois-Mouthon, C., Cadoret, A., Blivet-Van Eggelpoel, M.J., Bertrand, F., Cherqui, G., Perret, C., and Capeau, J. 2001. Insulin and IGF-1 stimulate the $\beta$-catenin pathway through two signaling cascades involving GSK-3 $\beta$ inhibition and Ras activation. Oncogene, 20: 252-259.

Froesch, E.R., Schmid, C., Schwander, J., and Zapf, J. 1985. Actions of insulin-like growth factors. Annu. Rev. Physiol., 47: 443-467.

Geffen, I. and Spiess, M. 1992. Asialoglycoprotein receptor. Int. Rev. Cytol., 137B: 181-219.

Hansen, L.K. and Albrecht, J.H. 1999. Regulation of the hepatocytes cell cycle by type-1 collagen matrix: role of cyclin D1. J. Cell Sci., 112: 2971-2981.

Hansen, L.K., Mooney, D.J., Vacanti, J.P., and Ingber, D.E. 1994. Integrin binding and cell spreading on extracellular matrix act at different points in the cell cycle to promote hepatocytes growth. Mol. Biol. Cell., 5: 967975.

Hiscow, S. and Jiang, W.G. 1997. Expression of E-cadherin, alpha, beta and gamma-catenin in human colorectal cancer. Anticancer Res., 17: 1349-1354.

Kamai, Y., Mikawa, S., Endo, K., Sakai, H., and Komano, T. 1996. Regulation of insulin-like growth factor-1 expression in mouse preadipocyte Ob1771 cells. J. Biol. Chem., 271: 9883-9886.

Kobayashi, A., Goto, M., Kobayashi, K., and Akaike, T. 1994. Receptormediated regulation of differentiation and proliferation of hepatocytes by synthetic polymer model of asialoglycoprotein. J. Biomater. Sci. Polym. Ed., 6: 325-342.

Kobayashi, A., Kobayashi, K., and Akaike, T. 1992. Control of adhesion and detachment of parenchymal liver cells using lactose-carrying polystyrene as substratum. J. Biomater. Sci. Polym. Ed., 3: 499-508.

Kobayashi, K., Kobayashi, A., and Akaike, T. 1994. Culturing hepatocytes on lactose-carrying polystyrene layer via asialoglycoprotein receptormediated interactions. Meth. Enzymol., 247: 409-418.
Kubota, S., Tashiro, K., and Yamada, Y. 1992. Signaling site of laminin with mitogenic activity. J. Biol. Chem., 267: 4285-4288.

Kuemmerle, J.F. and Bushman, T.L. 1998. IGF-1 stimulates intestinal muscle cell growth by activating distinct PI 3-kinase and MAP kinase pathways. Gastrointest. Liver Physiol. (Am. J. Physiol.), 38: 151-158.

Li, S., Braverman, R., Li, H., Vass, W.C., Lowy, D.R., and Declue, J.E. 2003. Regulation of cell morphology and adhesion by the tuberous sclerosis complex (TS1/2) gene products in human kidney epithelial cells through increased E-cadherin/ $\beta$-catenin activity. Mol. Carc., 37: 98-109.

Morita, M., Watanabe, Y., and Akaike, T. 1994. Inflammatory cytokines up-regulate intercellular adhesion molecule-1 expression on primary cultured mouse hepatocytes and T-lymphocyte adhesion. Hepatology, 19: $426-431$.

Muir, D., Varon, S., and Manthorpe, M. 1990. An enzyme-linked immunosorbent assay for bromodeoxyuridine incorporation using fixed microcultures. Anal. Biochem., 185: 377-382.

Napier, J.R., Thomas, M.F., Sharma, M., Hodgkinson, S., and Bass, J.J. 1999. Insulin-like growth factor-1 protects myoblast from apoptosis but requires other factors to stimulate proliferation. J. Endocrinol., 163: 6368.

Playford, M.P., Bicknell, D., Bodmer, W.E., and Macaulay, V.M. 2000. Insulin-like growth factor-1 regulates the location, stability, and transcriptional activity of $\beta$-catenin. Proc. Natl. Acad. Sci. USA, 97: 12103 12108.

Poizios, K.C., Ding, J., Degger, B., Upton, Z., and Duan, C. 2001. IGFs stimulate zebrafish cell proliferation by activating MAP kinase and PI3kinase-signaling pathways. Am. J. Physiol. Regulatory Interactive Comp. Physiol., 280: 1230-1239.

Sjorgren, K., Liu, J., Blad, K., Skrtic, S., Vidal, O., Wallenius, V., LeRoith, D., Tornell, J., Isaksson, O., Jansson, J.O., and Ohlsson, C. 1999. Liverderived IGF-1 is the principal source of IGF-1 in the blood but is not required for postnatal body growth in mice. Proc. Natl. Acad. Sci. USA, 96: 7088-7092.

Soni, P., Lakkis, M., Poy, M.N., Fernstrom, M.A., and Najjar, S.M. 2000 The differential effects of pp120 (Ceacam1) on the mitogenic action of insulin and insulin-like growth factor-1 are regulated by the nonconserved tyrosine 1316 in the insulin receptor. Mol. Cell. Biol., 20: 3896 3905.

Stockert, R.J. 1995. The asialoglycoprotein receptor: Relationships between structure, function and expression. Physiol. Rev., 75: 591-609.

Taylor, W.R. and Alexander, R.W. 1993. Autocrine control of wound repairs by insulin like growth factor-1 in cultured endothelial cells. Am. J. Physiol., 265: 801-805.

Watanabe, Y., Liu, X., Shibuya, I., and Akaike, T. 2000. Functional evaluation of poly-( $N$ - $p$-vinylbenzyl- $O$-beta-D-galactopyranosyl-[1-4]-Dgluconamide) (PVLA) as a liver specific carrier. J. Biomater. Sci. Polym. Ed., 11: 833-848.

Werner, H. and LeRoith, D. 1997. The insulin-like growth factor-1 receptor signaling pathways are important for tumorigenesis and inhibition of apoptosis. Crit. Rev. Oncog., 8: 71-92.

Wijnhoven, B.P.L., Dinjens, W.N.M., and Pignatelli, M. 2000. E-cadherin cell-cell adhesion complex and human cancer. Br. J. Surg., 87: 9921005 .

(Received for publication, July 22, 2003 and accepted, August 25, 2003) 